\title{
Molecular data attest to the occurrence of autochthonous Daphnia pulex (Crustacea, Branchiopoda) populations in Sicily, Italy
}

\author{
Luca Vecchioni, ${ }^{*}$ Marco Arculeo, Federico Marrone \\ Department of Biological, Chemical and Pharmaceutical Sciences and Technologies, University of Palermo, via Archirafi 18, 90123 \\ Palermo, Italy
}

\begin{abstract}
Biological invasions are known to be among the most important threats to the long-term conservation of native biota, and their effects might be even more difficult to contrast when they are cryptic, i.e., when the non-native invaders cannot be easily recognised based on morphology, and can thus be confused with native taxa. Such cryptic invasions are known to widely occur in the cladoceran genus Daphnia O.F. Müller, 1785, so that the actual distribution and status of most species and lineages need to be checked with a genetic approach. In the frame of this work, we investigated if the Sicilian populations of $D$. (Daphnia) pulex Leydig, 1860 belonged to the allochthonous North American lineage, which is known to occur in several regions of the Palearctic and Afrotropical biogeographical regions, or rather to the autochthonous European lineage of the species. The molecular results obtained, based on a fragment of the mitochondrial gene encoding for NADH subunit dehydrogenase 5 (ND5), allowed us to rule out the allochthonous status of the species, confirming the presence of autochthonous relictual lineages of $D$. pulex in Sicily. The native status of these populations is in agreement with their local distribution, limited to natural and poorly-impacted water bodies mostly located in wooded areas at medium and high altitudes. The current local distribution of $D$. pulex in Sicily is possibly linked to the end of the last glacial maximum and the onset of warmer climatic conditions in the early Holocene, which led the species to take refuge in colder microthermal refugia located at high altitudes, determining their current relictual distribution.
\end{abstract}

\section{INTRODUCTION}

Italian inland waters are known to be heavily affected by the occurrence of non-indigenous species (NIS) (Gherardi et al., 2007). These biological invaders are one of the major threats to native freshwater fauna, altering the habitat structure and assemblage composition and ultimately leading to a significant loss of native biodiversity (NaselliFlores and Marrone, 2019 and references therein).

Italy is characterized by a rich fauna of Cladocera, which includes 17 Daphnia O.F. Müller, 1785 species belonging to the subgenera Daphnia s.s. and Ctenodaphnia, plus several subspecies or hybrid taxa of dubious taxonomical value (Ruffo and Stoch, 2005; Marrone et al., 2007). Within the species belonging to the genus Daphnia s.s. occurring in Italy, two are allochthonous taxa of Nearctic origin, i.e., D. ambigua Scourfield, 1947 and D. parvula Fordyce, 1901 (Margaritora, 1985; Riccardi et al., 2004). Furthermore, the presence of a non-native lineage of American origin within D. pulex Leydig, 1860 was recorded in Sardinia and Piedmont (Fadda et al., 2011; Marková et al., 2013).

To date, the only non-native cladocerans positively known to occur in Sicily are Daphnia parvula and D. ambigua (Marrone et al., 2006; Marrone and Naselli-Flores, 2015), although also D. galeata G.O. Sars, 1864 and $D$. cucullata G.O. Sars, 1862 have a dubious status in the region (Marrone and Vecchioni, 2020). Moreover, no molecular data are to date available on the Sicilian populations of $D$. pulex, so that no information about the native or non-native status of Sicilian $D$. pulex is available. Furthermore, it must be taken into account that the taxonomy of the Daphnia pulex complex is rather difficult due to the absence of clear morphological features distinguishing among taxa listed under Daphnia pulex (CondePorcuna et al., 2020 and reference therein), a binomen which is misleadingly used for distinct different evolutionary lineages belonging to different biogeographical regions (Mergeay et al., 2008; Crease et al., 2012; Ma et al., 2019). Among them, the Nearctic lineage has been introduced in several countries, attaining an almost worldwide distribution with the sole exception of Antarctica (Crease et al., 2012; Conde-Porcuna et al., 2020).

In the light of the evidence of the presence of the allochthonous North American lineage of Daphnia pulex in Italian mainland and Sardinia (Fadda et al., 2011; Marková et al., 2013, 2017), the aim of this work was to identify the Daphnia lineages occurring in the Sicilian populations using a mitochondrial molecular marker, and thus verifying whether the evolutionary lineages occurring in Sicily belong to the allochthonous Nearctic or the autochthonous European groups. Accordingly, we carried out samplings in a selection of the known sites of occurrence of the species, and in an unpublished site where the species was found to occur.

\section{METHODS}

Based on the data available in the literature, Daphnia pulex is currently known for 19 sites in Sicily, which are limited to medium-high altitudes of the Nebrodi area, Madonie area, Etna and Bosco della Ficuzza (Marrone and Vecchioni, 2020). The populations from which samples of Daphnia pulex to be molecularly characterized 
were collected were chosen based on the known occurrence sites, with the aim of including in the analyses at least a population from each of the four major distribution subareas of the species on the island. In addition, one unpublished site of occurrence was found in the context of this sampling campaign ("ME076" - $37.94158 \mathrm{~N}$, 14.683676 E - $1559 \mathrm{~m}$ a.s.1.). A map of the known and sampled occurrence Sicilian sites of the species was made using QGIS software v. 3.18 (http://www.qgis.org).

Microcrustaceans were collected both in open waters and in the littoral areas of each water body through the use of hand- and lor towing-plankton nets with a mesh size of 125-200 $\mu \mathrm{m}$, depending on size, depth and vegetation cover of the sampled sites. The collected samples were fixed in situ with $96 \%$ ethanol and microcrustaceans were sorted out in laboratory under a stereomicroscope. Cladocera were morphologically identified according to Margaritora (1985), Alonso (1996), and Benzie (2005). All the studied samples are currently stored in FM's branchiopod collection at the University of Palermo, Italy, and are available for loan on request.

A single $D$. pulex individual from each population was carefully cleaned of any impurities and soaked in doubledistilled water for 5-10 minutes in order to eliminate the residual ethanol, and then processed for DNA extraction using the BIORON GmbH "Ron's Tissue DNA Mini Kit", following the manufacturer's instructions. The selective amplification of a fragment from the gene encoding NADH subunit dehydrogenase 5 (ND5), was carried out by polymerase chain reaction (PCR) using the primers ND5newF (5'-AAA CCT CTA AAB TTC YKA RCT- 3 ') and ND5newR (5'-CAT RTT YAT RTC RGG GGT TGT- 3'), described by Dufresne et al. (2011).

The PCR mix consisted of $18.9 \mu$ of distilled water, $2.5 \mu \mathrm{l}$ of Buffer $10 \mathrm{X}$ which includes $15 \mathrm{mM}$ of $\mathrm{MgCl}_{2}$, $0.4 \mu \mathrm{l}$ of dNTPs (10 mM for each), $0.4 \mu \mathrm{l}$ of each of the primers $(10 \mu \mathrm{M}), 0.4 \mu \mathrm{l}$ of Taq polymerase $(5 \mathrm{U} / \mu \mathrm{l})$ and $2 \mu \mathrm{l}$ of template DNA, for a total volume of $25 \mu \mathrm{l}$. The thermal cycle consisted of 35 cycles of denaturation $\left(94^{\circ} \mathrm{C}\right.$ for $1 \mathrm{~min})$, annealing $\left(50^{\circ} \mathrm{C}\right.$ for $\left.1 \mathrm{~min}\right)$ and extension $\left(72^{\circ} \mathrm{C}\right.$ for $1 \mathrm{~min}$ ), followed by five minutes at $72^{\circ} \mathrm{C}$ for the final extension step.

After PCR, $5 \mu \mathrm{l}$ of each PCR product were used to perform electrophoresis on $2 \%$ agarose gel at $90 \mathrm{~V}$ for 20 min and then visualized with a UV transilluminator. When PCR products showed a clear single band, of the expected length, they were purified using the Exo-SAP-IT ${ }^{\circledR}$ kit (Affymetrix USB, Santa Clara, CA, USA). Sequencing was performed by Macrogen Inc. (Madrid, Spain; https://dna.macrogen.com/eng/) using an ABI 3130xL (Applied Biosystems, Waltham, MA, USA) sequencer. The same primers used previously for PCR were subsequently used for direct sequencing of the PCR products.

The quality of the obtained chromatograms was checked through the measurement of their "Phred score" (Richterich, 1998). Only those sequences that showed continuous high quality base readings $(\mathrm{QV}>20)$ were used. Chromatograms were analysed and manually proofread using the software Chromas software v. 2.6.2 (Technelysium, Pty. Ltd., South Brisbane, Australia). Overall, six novel ND5 sequences of Daphnia pulex were produced. Moreover, in order to compare the new sequences with those publicly available, ten Daphnia pulex sequences, eight $D$. pulicaria Forbes, 1893 sequences, four D. tenebrosa Sars, 1898 sequences and one D. magna Straus, 1820 sequence (used as an outgroup) were downloaded from GenBank and included in the analyses (see Tab. 1 for their Accession Number, A.N.).

All sequences were aligned with MEGAX software (Kumar et al., 2018) using the ClustalW method (Thompson et al., 1997).

MrBayes software v. 3.2.6 (Ronquist et al., 2012) and PhyML v. 3 (Guindon and Gascuel, 2003) were used for inferring the molecular identification and phylogenetic relationships between taxa, using Bayesian Inference (BI) and Maximum Likelihood (ML) analyses. As support measures for the nodes, bootstrap values (Felsenstein, 1985) were calculated with 1000 replicates in ML trees, while the posterior probability values were reported in the BI tree. PartitionFinder v. 1.0.1 (Lanfear et al., 2012) was used to choose the best evolutionary model following the "Akaike Information Criterion" (AIC; Akaike, 1974). A Hasegawa - Kishino - Yano evolutionary sequence model with a proportion of gamma and invariant sites $(\mathrm{HKY}+\mathrm{I}+\Gamma ; \mathrm{nst}=2)$ was used in the BI and ML analyses. In the BI analysis, two independent Markov Chain Monte Carlo analyses were performed with 1 million generations (temp.: 0.2; default priors). The trees and parameter values were sampled every 100 generations, resulting in 10,000 trees for each analysis. The convergence in the analysis was reached (Effective Sample Size (ESS) greater than 533.13 in all the analyses performed). The initial $25 \%$ of trees were discarded as "burn-in".

\section{RESULTS}

In addition to five of the published sites from the Madonie, Nebrodi and Bosco della Ficuzza areas, the species was collected in an novel site on the Nebrodi mountains (ME076), located close to the site "ME004", where the species was already known to occur (see Tab. 1 in Marrone and Vecchioni, 2020). In all the sampled populations, parthenogenetic females coexisted with males and ephippial females. Unfortunately, logistic constraints made not possible to collect fresh samples in the only known site for the species within the Etna area (CT011, see Tab. 1 in Marrone and Vecchioni, 2020), which was thus not included in the analyses. 
Overall, six new sequences belonging to Daphnia pulex were produced from six different Sicilian water bodies (Fig. 1, Tab. 1). After having trimmed out the sequences, a properly aligned fragment of $624 \mathrm{bp}$ long of the ND5 mtDNA gene was obtained. Novel sequences were deposited in GenBank (A.N., MZ489122MZ489127).

The BI and ML trees based on the mitochondrial ND5 mtDNA fragment and rooted on D. magna showed a congruent and well supported topology highlighting how the analysed sequences of Daphnia pulex s.l. create two paraphyletic clades: the first including North American $D$. pulex populations and the allochthonous North American D. pulex populations occurring in Europe ("NAPX"); the second one includes the autochthonous European D. pulex populations ("EPX") including the analysed Sicilian populations (i.e., PA074, PA079, PA081, ME004, ME013, ME076; Tab. 1). All the Sicilian sequences clustered to- gether in a monophyletic clade showing only two slightly different haplotypes (i.e., there is only a single base of difference between the sequence that belongs to PA079 and the remaining ones).

Similarly to what was observed in D. pulex, also $D$. pulicaria shows a marked paraphyly (Fig. 2) that separates the North American populations ("NAPC") from the European ones ("EPC").

\section{DISCUSSION}

Based on the molecular evidence here reported, the Sicilian populations of Daphnia pulex unequivocally belong to the native European lineage.

Taking into account the distribution of the species in Sicily, this result is not surprising. In fact, Sicilian $D$. pulex populations seem to be linked to natural, poorly-

Tab. 1. Origin and GenBank accession numbers (A.N.) for the analysed Daphnia specimens. Geographic coordinates are expressed as decimal degrees (Map Datum: WGS84).

\begin{tabular}{|c|c|c|c|c|c|c|c|}
\hline Taxon & Country & Location & Latitude (N) & Longitude (E) & A.N. & Clade & Reference \\
\hline \multirow{8}{*}{ D. pulicaria } & Albania & Ohrid & 40.95 & 20.71 & KC536551 & $\mathrm{EPC}$ & Marková et al., 2013 \\
\hline & Switzerland & Alps & 46.67 & 8.04 & KC536536 & $\mathrm{EPC}$ & Marková et al., 2013 \\
\hline & Czech Republic & Bohdaneč & 49.78 & 15.23 & KC536543 & EPC & Marková et al., 2013 \\
\hline & Italy & Dolomites & 46.48 & 11.66 & KC536525 & $\mathrm{EPC}$ & Marková et al., 2013 \\
\hline & Greenland & Nuuk & 64.15 & -51.31 & KC536586 & $\mathrm{EPC}$ & Marková et al., 2013 \\
\hline & Canada & Winnipeg, Manitoba & 52.12 & -97.25 & KC536611 & NAPC & Marková et al., 2013 \\
\hline & USA & Indiana & 39.9 & -85.43 & KC536600 & NAPC & Marková et al., 2013 \\
\hline & Iceland & Reykjavik & 64.13 & -21.94 & KC536621 & NAPC & Marková et al., 2013 \\
\hline \multirow[t]{24}{*}{ D. pulex } & Czech Republic & Blatná & 49.42 & 13.78 & KC536544 & EPX & Marková et al., 2013 \\
\hline & Germany & Regensburg & 49 & 12.15 & KC536593 & EPX & Marková et al., 2013 \\
\hline & UK & Streetly End & 52.14 & 0.35 & KC536555 & EPX & Marková et al., 2013 \\
\hline & Lithuania & Vilnius & 54.75 & 25.29 & KC536560 & EPX & Marková et al., 2013 \\
\hline & Canada & Listowel pond, Ontario & 43.73 & -80.95 & KC536602 & NAPX & Marková et al., 2013 \\
\hline & Canada & Disputed Road, Ontario & 42.22 & -83.03 & HQ434640 & NAPX & Vergilino et al., 2011 \\
\hline & Canada & Res. Duchesnier, Quebec & 48.13 & -68.63 & KC536603 & NAPX & Marková et al., 2013 \\
\hline & Italy & PA079 & 37.889944 & 13.394575 & MZ489122 & EPX & Present work \\
\hline & Italy & PA074 & 37.823410 & 14.127241 & MZ489123 & EPX & Present work \\
\hline & Italy & PA081 & 37.901131 & 13.408438 & MZ489124 & EPX & Present work \\
\hline & Italy & ME013 & 37.951944 & 14.698331 & MZ489125 & EPX & Present work \\
\hline & Italy & ME076 & 37.941580 & 14.683670 & MZ489126 & EPX & Present work \\
\hline & Italy & ME004 & 37.939456 & 14.682634 & MZ489127 & EPX & Present work \\
\hline & Italy & Avigliana & 45.070000 & 7.390000 & $\mathrm{KC} 536565 \mathrm{a}$ & NAPX & Marková et al., 2013 \\
\hline & Italy & Sardinia & 40.560000 & 9.320000 & KC536565b & NAPX & Marková et al., 2013 \\
\hline & Italy & Bodrio del Pastore III & 45.001389 & 10.323889 & KR233296 & EPX & Marková et al., 2017 \\
\hline & Spain & Lake Borreguil, Sierra Nevada & 37.052 & -03.30 & MW883468 & NAPX & Conde-Porcuna et al., 2021 \\
\hline & Sweden & - & - & - & HQ434644 & EPX & Vergilino et al., 2011 \\
\hline & Kenya & Lake Naivasha & -0.771667 & 36.361667 & DQ235240 & NAPX & Mergeay et al., 2006 \\
\hline & South Africa & Cape Flats & -33.98 & 18.656667 & DQ235233 & NAPX & Mergeay et al., 2006 \\
\hline & Kenya & Lake Baringo & 0.535764 & 36.063759 & DQ235242 & NAPX & Mergeay et al., 2006 \\
\hline & Japan & Kosugi, Toyama & 36.68 & 137.09 & JX532913 & NAPX & Crease et al., 2012 \\
\hline & Japan & Higashi Hiroshima, Hiroshima & 34.35 & 132.8 & JX532907 & NAPX & Crease et al., 2012 \\
\hline & China & Lake Wusutu & 40.86 & 111.55 & MH632088 & NAPX & Ma et al., 2019 \\
\hline \multirow[t]{4}{*}{ D. tenebrosa } & Canada & Churchill, Manitoba & 58.77 & -94.17 & KC536605 & - & Marková et al., 2013 \\
\hline & Russia & Petchora Delta & 68.06 & 53.58 & KC536564 & - & Marková et al., 2013 \\
\hline & Svalbard & Storvatnet, Ny-Alesund & 78.92 & 11.88 & KC536580 & - & Marková et al., 2013 \\
\hline & Russia & Tsvetkov cape, Taimyr & 74.92 & 112.62 & KC536608 & - & Marková et al., 2013 \\
\hline D. magna & - & - & - & - & MT199637 & - & Lee (Unpublished) \\
\hline
\end{tabular}


mineralized ponds located within wooded areas at medium and high altitudes (Marrone and Vecchioni, 2020), where phenomena of biological invasions are less frequent than in disturbed water bodies located in highlyanthropized areas. In fact, in Italy, the non-native D. pulex lineage was to date found in artificial or highly-anthropized water bodies both in Sardinia and Piedmont (Fadda et al., 2011; Marková et al., 2017). In light of these results, the hypothesis by Marrone et al. (2009) that Sicilian $D$. pulex populations are relictual elements that colonised Sicily during the late Pleistocene glacial events, coming from the Balkan peninsula or northern Italy, and which later found a "cool" refuge at higher altitude with the onset of warmer and low-moisture climatic conditions in the early Holocene (Curry et al., 2016), seems to be supported.

Interestingly, based on the currently available data, it seems that native European D. pulex populations preferentially inhabit small, natural water bodies, whereas the populations of the non-native American lineage are mostly occurring in artificial or highly-disturbed habitats (Schwenk et al., 2000; Fadda et al., 2011; Vergilino et al., 2011) at medium and low altitude with a single high-altitude exception reported for a Spanish lake located in the Sierra Nevada (Conde-Porcuna et al., 2020). Native and non-native $D$. pulex lineages are known to coexist sympatrically, but not syntopically, in the Po River basin, with the native populations occurring in the "bodri" (i.e., temporary natural ponds) (Marková et al., 2017), and the nonnative one found in the highly-anthropized Avigliana lakes (Virgilino et al., 2011; Marková et al., 2013). Conversely, for Sardinian populations molecular data are available only from a single site, i.e., an artificial reservoir built in Sos Canales (Fadda et al., 2011). However, D. pulex is also occurring in smaller, natural astatic and temporary ponds located in the southern part of the island (Margaritora et al., 2021; Marrone and Stoch, unpublished data), and it should be checked whether the D. pulex populations inhabiting these marginal, natural habitats belong to the alien or the native lineage.

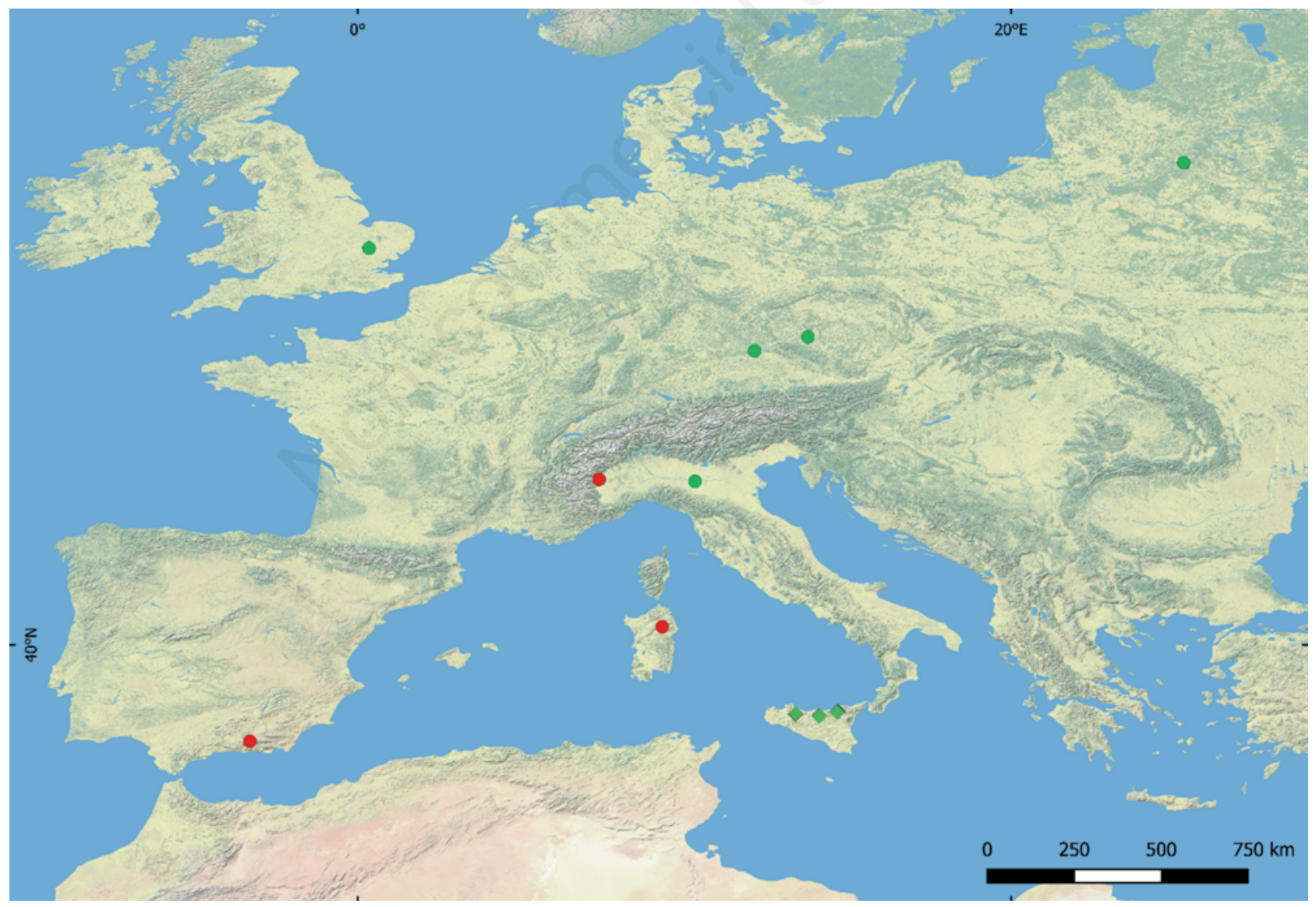

Fig. 1. Geographic location of Daphnia pulex sampling sites for which molecular data are available. Red circles indicate sites where the North American lineages, "NAPX", of Daphnia pulex occur. Green circles and diamonds indicate where the European lineages, "EPX", of the species occur. Green diamonds indicate the novel sampled sites. Due to the scale of the map some of the novel sites overlap and thus are not displayed. See Tab. 1 for the coordinates of the sampling sites and for more information on the collected species. 


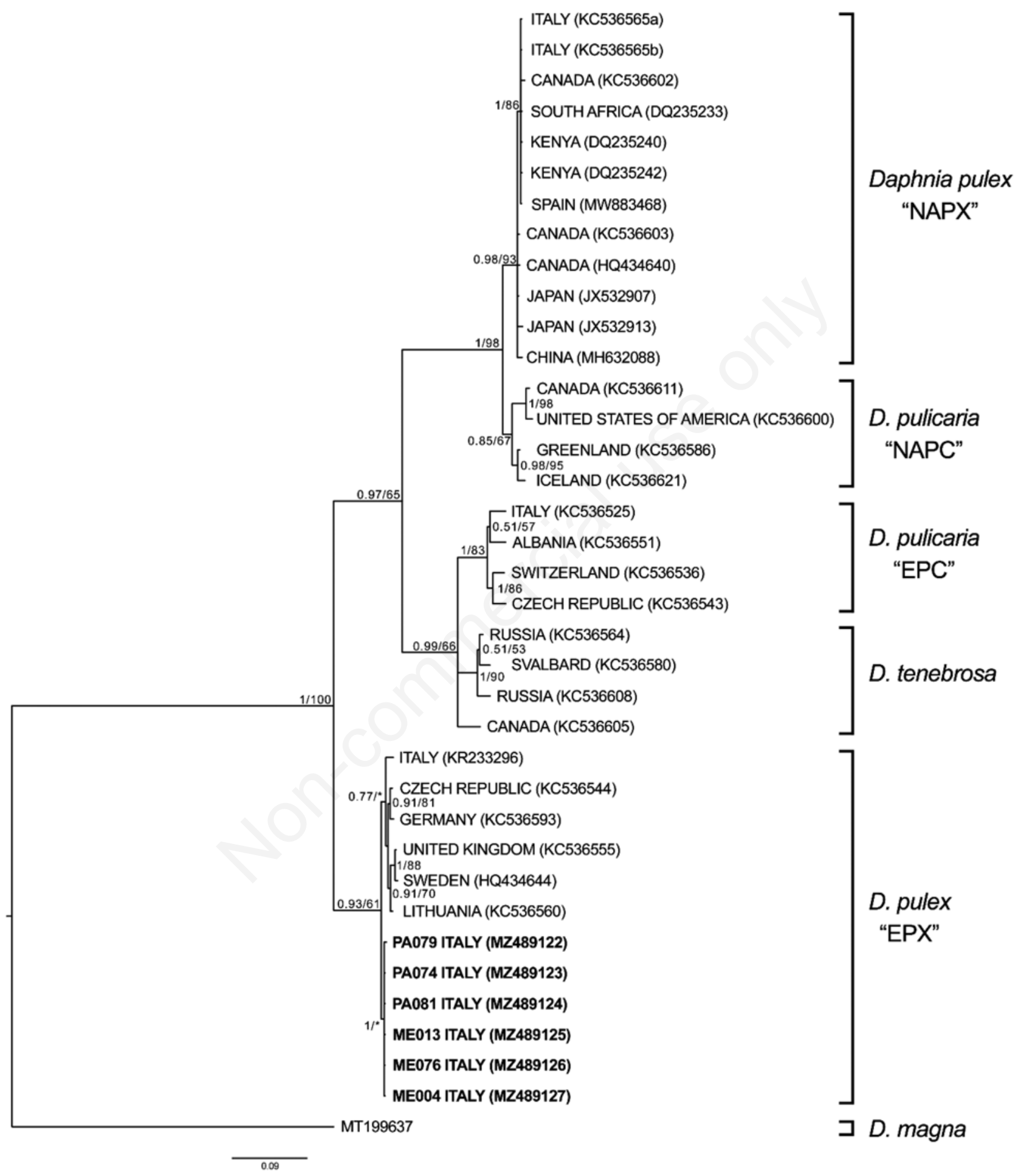

Fig. 2. Bayesian phylogram of Daphnia spp. based on the $624 \mathrm{bp}$ fragment of the mtDNA ND5. D. magna was used as outgroup. Node statistical support is reported as nodal posterior probabilities (Bayesian Inference of phylogeny, BI)/bootstrap values (Maximum Likelihood, ML). *, Nodal statistical supports $<0.50$. Square brackets group the samples according to the current taxonomy of the genus. Novel sequences are reported in bold. NAPX, North American Pulex; NAPC, North American Pulicaria; EPX, European Pulex; EPC, European Pulicaria. The analysed specimens are reported using the codes listed in Tab. 1. 


\section{CONCLUSIONS}

This study provides the first molecular data about the Sicilian populations of the water flea Daphnia pulex. All the sampled populations proved to belong to the autochthonous European lineage of the species, in accordance with their previously hypothesised native and relictual status (Marrone et al., 2009; Marrone and Vecchioni, 2020). Sicilian D. pulex populations are thus important management units, to be attentively managed and preserved. Considering the threats to native taxa linked with the occurrence and spreading of invasive, alien species (Marrone and Naselli-Flores, 2015), and the importance of timely acting to have a chance to effectively manage the biological invasions, the molecular characterization of the D. pulex populations occurring in southern Sardinia, peninsular Italy, and Malta (Margaritora et al., 2021) is urgent and desirable.

\section{ACKNOWLEDGMENTS}

Sara La Franca is acknowledged for the help she provided during the preparation of this manuscript. Two anonymous reviewers are acknowledged for their comments to a first draft of the manuscript.

\section{CONFLICT OF INTEREST}

The authors declare no competing interests.

Corresponding author: luca.vecchioni@unipa.it

Keywords: Cladocera; Anomopoda; biological invasions; cryptic invasions.

Received: 1 July 2021

Accepted: 14 September 2021.

This work is licensed under a Creative Commons Attribution NonCommercial 4.0 License (CC BY-NC 4.0).

${ }^{\circ}$ Copyright: the Author(s), 2021

Licensee PAGEPress, Italy

Advances in Oceanography and Limnology, 2021; $12: 9947$

DOI: 10.4081/aiol.2021.9947

\section{REFERENCES}

Akaike H, 1974. A New look at the statistical model identification. IEEE Trans. Automat. Contr. 19:716-723.

Alonso M, 1996. Crustacea, Branchiopoda. Fauna Iberica 7. Museo Nacional de Ciencias Naturales, CSIC, Madrid, 486 pp.

Benzie JAH, 2005. Cladocera: the genus Daphnia (including Daphniopsis). Guides to the identification of the Microin- vertebrates of the Continental Waters of the World. Backhuys Publishers, Leiden: 376 pp.

Conde-Porcuna JM, Veiga J, Moreno E, Jiménez L, Ramos-Rodríguez E, Pérez-Martínez C, 2021. Spatiotemporal genetic structure in the Daphnia pulex complex from Sierra Nevada lakes (Spain): reproductive mode and first record of North American D. cf. pulex in European alpine lakes. J. Plankton Res. 43:380-395.

Crease TJ, Omilian AR, Costanzo KS, Taylor DJ, 2012. Transcontinental phylogeography of the Daphnia pulex species complex. PLoS One 7:e46620.

Curry B, Henne PD, Mesquita-Joanes F, Marrone F, Pieri V, La Mantia T, Calò C, Tinner W, 2016. Holocene paleoclimate inferred from salinity histories of adjacent lakes in southwestern Sicily (Italy). Quat. Sci. Rev. 150: 67-83.

Dufresne F, Marková S, Vergilino R, Ventura M, Kotlík P, 2011. Diversity in the reproductive modes of European Daphnia pulicaria deviates from the geographical parthenogenesis. PLoS One 6:e20049.

Fadda A, Marková S, Kotlík P, Lugliè A, Padedda B, Buscarinu P, Sechi N, Manca M, 2011. First records of planktonic crustaceans in Sardinian reservoirs. Biologia 66:856-865.

Felsenstein J, 1985. Confidence limits on phylogenies: An approach using the bootstrap. Evolution 39:783-791.

Gherardi F, Bertolino S, Bodon M, Casellato S, Cianfanelli S, Ferraguti M, Lori E, Mura G, Nocita A, Riccardi N, Rossetti G, Rota E, Scalera R, Zerunian S, Tricarico E, 2007. Animal xenodiversity in Italian inland waters: distribution, modes of arrival, and pathways. Biol. Invasions 10:435-454.

Guindon S, Gascuel O, 2003. A simple, fast, and accurate algorithm to estimate large phylogenies by maximum likelihood. Syst. Biol. 52:696-704.

Kumar S, Stecher G, Li M, Knyaz C, Tamura K, 2018. MEGA $\mathrm{X}$ : Molecular evolutionary genetics analysis across computing platforms. Mol. Biol. Evol. 35:1547-1549.

Lanfear R, Calcott B, Ho SYW, Guindon S, 2012. PartitionFinder: Combined selection of partitioning schemes and substitution models for phylogenetic analyses. Mol. Biol. Evol. 29:1695-1701.

Ma XL, Petrusek A, Wolinska J, Hu W, Yin MB, 2019. Lineage diversity and reproductive modes of the Daphnia pulex group in Chinese lakes and reservoirs. Mol. Phylogenet. Evol. 130:424-433.

Margaritora FG, 1985. Cladocera. Fauna d'Italia, Ed. Calderini, Bologna, 399 pp.

Margaritora FG, Vagaggini D, Stoch F, 2021. Crustacea Branchiopoda Cladocera. In: Bologna MA, Zapparoli M, Oliverio M, Minelli A, Bonato L, Cianferoni F, Stoch F. (eds.), Checklist of the Italian Fauna. Version 1.0. Last update: 2021-05-31.

Marková S, Dufresne F, Manca M, Kotlik P, 2013. Mitochondrial capture misleads about ecological speciation in the Daphnia pulex complex. PLoS One 8:e69497.

Marková S, Maurone C, Racchetti E, Bartoli M, Rossi V, 2017. Daphnia diversity in water bodies of the Po River Basin. J. Limnol. 76:261-271.

Marrone F, Alfonso G, Naselli-Flores L, 2007. On Daphnia (Ctenodaphnia) similis Claus, 1877 and other interesting anomopods (Crustacea, Branchiopoda) from Apulia (Southern Italy). Thalassia Salentina 30: 45-55. 
Marrone F, Barone R, Naselli-Flores L, 2006. Ecological characterization and cladocerans, calanoid copepods and large branchiopods of temporary ponds in a Mediterranean island (Sicily, Southern Italy). Chem. Ecol. 22:181-190.

Marrone F, Castelli G, Naselli-Flores L, 2009. Sicilian Temporary Ponds: an overview on the composition and affinities of their crustacean biota, p. 189-202. In: Fraga I, Argiumbau P. (eds.), International Conference on Mediterranean Temporary Ponds. Proceedings \& Abstracts. Consell Insular de Menorca. Recerca, 14. Maó, Menorca.

Marrone F, Naselli-Flores L, 2015. A review on the animal xenodiversity in Sicilian inland waters (Italy). Adv. Oceanogr. Limnol. 6:5451.

Marrone F, Vecchioni L, 2020. The genus Daphnia in Sicily and Malta (Crustacea, Branchiopoda, Anomopoda). pp. 105-124 in: La Mantia et al. (eds.), Life on Islands, 1. Biodiversity in Sicily and surrounding islands. Studies dedicated to Bruno Massa. Edizioni Danaus, Palermo.

Mergeay J, Aguilera X, Declerck S, Petrusek A, Huyse T, De Meester L, 2008. The genetic legacy of polyploid Bolivian Daphnia: the tropical Andes as a source for the North and South American D. pulicaria complex. Mol. Ecol. 17:1789-1800.

Mergeay J, Verschuren D, De Meester L, 2006. Invasion of an asexual American water flea clone throughout Africa and rapid displacement of a native sibling species. Proc. R. Soc. Lond. B. Biol. Sci. 273:2839-2844.

Naselli-Flores L, Marrone F, 2019. Different invasibility of permanent and temporary waterbodies in a semiarid Mediterranean Island. Inland Waters 9:411-421.
QGIS Development Team (2018) QGIS Geographic Information System. Open-Source Geospatial Foundation Project. Available from: http://www.qgis.org/

Riccardi N, Giussani G, Margaritora F, Couchaud B, 2004. Population dynamics of the pioneer population of Daphnia parvula Fordyce during the invasion of Lake Candia (northern Italy). J. Limnol. 63:44-52.

Richterich P, 1998. Estimation of errors in "raw" DNA sequences: a validation study. Genome Res. 8:251-259.

Ronquist F, Teslenko M, Van Der Mark P, Ayres DL, Darling A, Höhna S, Larget B, Liu L, Suchard MA, Huelsenbeck JP, 2012. MrBayes 3.2: efficient Bayesian phylogenetic inference and model choice across a large model space. Syst. Biol. 61:539-542.

Ruffo S, Stoch F, 2005. [Checklist e distribuzione della fauna italiana].[Article in Italian]. Memorie del Museo Civico di Storia Naturale di Verona 2 Ser. Sez. Sci. Vita 16:1-307.

Schwenk K, Posada D, Hebert PDN, 2000. Molecular systematics of European Hyalodaphnia: the role of contemporary hybridization in ancient species. Proc. R. Soc. B 267:18331842.

Thompson JD, Gibson TJ, Plewniak F, Jeanmougin F, Higgins DG, 1997. The CLUSTAL X windows interface: Flexible strategies for multiple sequence alignment aided by quality analysis tools. Nucleic Acids Res. 25:4876-4882.

Vergilino R, Marková S, Ventura M, Manca M, Dufresne F, 2011. Reticulate evolution of the Daphnia pulex complex as revealed by nuclear markers. Mol. Ecol. 20:1191-1207. 